\title{
PENGARUH BAURAN PEMASARAN TERHADAP PROSES KEPUTUSAN PELANGGAN DALAM MEMILIH RAWAT INAP DI RUMAH SAKIT ISLAM IBNU SINA PADANG TAHUN 2012
}

\author{
Sry Rachmawaty ${ }^{1}$, Rima Semiarty ${ }^{2}$, Ratni Prima Lita ${ }^{3}$ \\ Program PascasarjanaS2 Kesehatan Masyarakat Fakultas Kedokteran Universitas Andalas ${ }^{1}$ \\ Dosen Fkonomi Fakultas Kedokteran Universitas Andalas ${ }^{2}$ \\ Dosen Fakultas Ekonomi Uni versitas Andalas ${ }^{3}$ \\ Email:erik.estrada1011@gmail.com Telp:08129092762
}

Submitted : 27-01-2020, Reviewer: 29-01-2020, Accepted: 30-01-2020

\begin{abstract}
Abstrak
Proses keputusan untuk memilih rawat inap bagi pelanggan bukanlah hal yang mudah. Banyak faktor yang harus dipertimbangkan untuk rawat inap di suatu rumah sakit. Penelitian ini bertujuan untuk mengetahui pengaruh bauran pemasaran terhadap keputusan pelanggan (pasien) dalam memilih rawat inap di Rumah Sakit Ibnu Sina Padang tahun 2012.

Penelitian ini adalah penelitian kuantitatif dengan metode field survey. Penelitian dilakukan di Rumah Sakit Ibnu Sina pada bulan Januari dan Februari 2012. Data primer dikumpulkan dengan cara menyebarkan kuisioner yang kemudian diolah dengan regresi linier berganda dalam metode enter, dimana hasil yang tidak signifikan dikeluarkan satu-persatu sampai mendapatkan variabel yang paling signifikan mempengaruhi keputusan untuk memilih diraw at inap di Rumah Sakit Ibnu Sina.

Pada penelitian ini didapatkan bahw a semua variable bauran pemasaran mempengaruhi keputusan memilih sebesar $80,5 \%$, sedangkan sisanya dipengaruhi oleh sebab lain yang tidak ikut diteliti. Namun dari ketujuh variabel pemasaran yang diuji, ada 3 (tiga) variabel yang sangat mempengaruhi pelanggan dalam memilih. variabel tersebut, yaitu: price, people, dan physical evidence. Diharapkan kepada Rumah Sakit Ibnu Sina Padang untuk menurunkan biaya layanan bagi pasien sesuai dengan staus sosial ekonomi masyarakat disekitar wilayah Rumah Sakit dan meningkatkan kualitas bukti fisik layanan kesehatan seperti peralatan yang representatif, interior bangunan yang asri, eksterior bangunan, fasilitas parkir, kantin, bank, dan jaminan keamanan.
\end{abstract}

Kata Kunci: Bauran Pemasaran, Proses Memilih Keputusan dan Rawat Inap

\begin{abstract}
The process of choosing hospitalization for customers is not a simple matter. Many factors are considered for being hospitalized. Unlike the other services' costumers, the hospital's costumers usually come in forced thus when they choose a hospital, they will prefer the one which can give them the fastest service. This research aims to find out and see the factors considered for selecting hospitalization in Ibnu Sina Hospital.

This research is a quantitative research by using field survey methods. The study was conducted at Ibnu Sina Hospital in January-February 2012. The primary data was collected by distributing questionnaires and processed by multiple linear regression of the enter method. Following that, the insignificant results were removed one by one until the most significant variables in affecting the decision to choose hospitalized in Ibnu Sina Hospital were obtained.

In this study, it is find that all of the seven marketing mix variables affect the costumer's decision to choose as percentage of $80,5 \%$, while the rest are influenced by other causes that are not part of the observation. However, over the seven marketing variables that have been observed, there are 3 (three) variables, which really influence the customer to choose. The variables are the 'price', 'people' and 'physical evidence'. Then, it can be suggested to establish reasonable prices in using the hospital services, not only the cost in terms of money, but also the cost of the psychological services, cost of the time services, cost of the physical services, and cost of the sensory services.
\end{abstract}


The hospital should always improve the skills of the hospital personnel. The personnel are also expected to be able to serve the customer in accordance with the missions and the visions of Ibnu Sina hospital. For the physical evidence, the hospital management can maintain and increase the level of safety, comfort, beauty of the hospitals, and provide an adequate waiting room for patient's watchman in order to maintain and increase all of the marketing mix variables which influence the decision of the costumer to choose, hence the costumer can choose and decide to be hospitalized in Ibnu Sina Hospital.

Keywords: Marketing mix, the decision process, hospitalization

\section{PENDAHULUAN}

Rumah sakit adalah sarana kesehatan yang menyelenggarakan pelayanan kesehatan secara merata, dengan mengutamakan upaya penyembuhan penyakit dan pemulihan kesehatan. Rumah sakit melaksanakan pelayanan kesehatan secara serasi dan terpadu dalam upaya peningkatan kesehatan dan pencegahan penyakit pada suatu tatanan rujukan, serta dapat dimanfaatkan untuk pendidikan dan penelitian. Dalam UndangUndang no 44 tentang rumah sakit disebutkan bahwa rumah sakit adalah institusi pelayanan kesehatan yang menyelenggarakan pelayanan kesehatan perseorangan secara paripurna dengan menyediakan pelayanan rawat inap, rawat jalan dan gawat darurat ${ }^{(1)}$.

Sangat penting bagi rumah sakit untuk mengetahui, mengenalikan kebutuhan dan keinginan konsumen sehingga memutuskan untuk memilih pelayanan kesehatan yang diselenggarakannya. Proses keputusan memilih layanan kesehatan bagi konsumen rumah sakit memiliki karakteristik yang sangat spesifik. Berbeda dengan pelanggan jasa lain, pelanggan atau pasien rumah sakit secara psikologis datang dalam keadaan "terpaksa", sehingga ketika memilih rumah sakit sangat sering tergantung pada kondisi dimana pasien ingin segera memperoleh penanganan medis. Keputusan pembelian produk tertentu ditimbulkan dari proses pengambilan keputusannya maka kedatangan pasien di rumah sakit biasanya bukan kehendak pribadi. Pada umumnya kedatangan pasien ke rumah sakit karena faktor penyakit yang $\operatorname{diderita}^{(2)}$. Keputusan pembelian oleh konsumen dalam hal ini disebut pasien bagi rumah sakit adalah keputusan memilih pelayanan jasa. Karakteristik jasa yang abstrak karena tidak dapat dimiliki, tidak berwujud, out put yang tidak tahan lama dan adanya kesamaan waktu produksi dan konsumsi, akan lebih menyulitkan konsumen untuk memilih pelayanan kesehatan rumah sakit. Memudahkan konsumen dalam memilih, maka konsumen akan mencari simbol-simbol yang dapat dikenalinya seperti dokter, tarif, pelayanan penunjang dan lain-lain. Pada rumah sakit yang berorientasi pemasaran holistik, setiap pelayanan kesehatan dan segmen pasarnya harus dikembangkan strategi pemasaran agar pelayanan kesehatan 
itu berhasil, salah satu komponen pemasaran holistik adalah mengembangkan bauran pemasaran (3)

Bauran pemasaran adalah seperangkat variabel yang dapat dikendalikan oleh perusahaan untuk menghasilkan tanggapan yang diinginkan oleh pelanggan. Bauran pemasaran mempunyai 7 variabel yaitu produk, price, place, promotion, people, process, dan physical evidence. Tujuan bauran pemasaran ialah melakukan penawaran (offer) dengan melakukan promosi dan distribusi produk dengan harapan terjadi akses berupa pembelian produk/jasa ${ }^{(4)}$.

Produk merupakan serangkaian produk dan unit produk yang ditawarkan rumah sakit bagi pasien. Produk rumah sakit antara lain, rawat jalan, rawat inap, laboratorium, layanan gizi, dan lain-lain. Sedangkan harga adalah sejumlah uang yang konsumen bayar untuk membeli produk atau mengganti hak milik produk. Promosi adalah mengkomunikasikan pesan tentang pengetahuan, keyakinan dan ingatan akan produk/jasa kepada pembeli potensial dengan tujuan mendapat tanggapan serta menimbulkan pengaruh sehingga membutuhkan dan memanfaatkan jasa pelayanan. Tempat adalah dimana terjadinya transaksi yang mempunyai arti penting karena lingkungan tempat jasa akan disampaikan dan cara jasa disampaikan. Pada people sebagai unsur pemasaran dikaitkan dengan pemasaran internal. Karena people diharapkan berperan sebagai penarik pelanggan untuk membeli produk yang ditawarkan oleh pihak rumah sakit. Sedangkan proses yaitu mengatur dan mengendalikan proses pelayanan rumah sakit agar mekanisme kegiatan pelayanan dapat berjalan tertib, lancar, tepat mengenai sasaran dan memuaskan bagi pihak yang harus yang harus dilayani. Physical evidence atau lingkungan fisik dari perusahaan jasa adalah tempat dimana pemberi jasa dan pelanggan berinteraksi. Pada rumah sakit lingkungan fisik mencakup peralatan dan fasilitas $^{(5)}$.

Rumah Sakit Islam Ibnu Sina Padang merupakan salah satu rumah sakit swasta di Padang. Rumah sakit yang sudah berdiri sejak tahun 1972 ini, menghadapi persaingan dengan rumah sakit swasta lainnya di Padang. Sejak tahun 2007 sampai dengan 2010 terjadi penurunan jumlah pelanggan rawat inap di Rumah Sakit Islam Ibnu Sina. Pemakaian tempat tidur (Bed Occupancy Rate) tahun 2007 sebesar 78,98\%, tahun 2008 angka Bed Occupancy Rate naik menjadi 79,33\%, tahun 2009 angka Bed Occupancy Rate menurun menjadi 74,90\%, tahun 2010 angka Bed Occupancy Rate turun menjadi 69,80\% dan tahun 2011 naik kembali menjadi 73,99\%. Jika dibandingkan dengan tahun 2009, titik Bed Occupancy Rate tahun 2010 menurun sebanyak $7,21 \%{ }^{(6)}$, keadaan ini disebabkan 
oleh berbagai faktor, salah satunya adalah peningkatan jumlah tempat tidur tahun 2010 secara resmi dari 63 tempat tidur menjadi 80 tempat tidur atau naik sebesar $12 \%$, namun kenaikan jumlah pasien yang dirawat hanya 5\% jadi tidak diikuti kenaikan jumlah kunjungan pelanggan di Rumah Sakit Ibnu Sina Padang.

Jumlah pelanggan rawat inap menurun walaupun sedikit, Hal ini menunjukkan rawat inap kurang efisien dalam pemanfaatan tempat tidur. Kondisi ini bila dibiarkan akan membawa kerugian bagi rumah sakit sendiri. Berdasarkan survey pendahuluan (Tahun 2010) penurunan pelanggan rawat inap diperkirakan karena bauran pemasaran belum optimal. Yang dimaksud dengan bauran pemasaran terdiri dari $7 \mathrm{p}$ yaitu; product, price, place, promotion, people, process, physical evidence, belum ada produk unggulan, tarif yang belum sesuai dengan pelayanan, lokasi rumah sakit yang tidak dipinggir jalan utama dengan akses jalan masuk yang kurang lapang. Promosi belum dilakukan secara baik ini terlihat dari belum adanya petunjuk jalan menuju kerumah sakit disetiap simpang jalan di kota Padang. Pelayanan personel rumah sakit yang belum optimal seperti keterlambatan visite dokter, sarana prasarana yang belum lengkap seperti di perinatologi, fasilitas fisik rumah sakit belum lengkap semisal belum memiliki CT Scan dan MRI.

METODE
Penelitian ini merupakan penelitian deskriptif dan explanatory untuk mendapatkan gambaran bauran pemasaran dominan yang dipilih oleh pelanggan untuk diusulkan sebagai pengembangan bauran pemasaran di Rumah Sakit Islam Ibnu Sina dan menguji pengaruh bauran pemasaran yang meliputi produk, harga, tempat, promosi, personel, proses dan bukti fisik terhadap proses keputusan pelanggan dalam memilih rawat inap di Rumah Sakit Ibnu Sina

Populasi yang diambil dalam penelitian ini adalah pasien rawat inap RS Ibnu Sina yang dirawat minimal 2 hari . Alasan dipilihnya instalasi rawat inap adalah pasien akan mendapatkan semua fasilitas layanan. Adapun rawat inap yang dijadikan populasi terdiri dari rawat inap VIP Khusus, VIP , Kelas Utama, Kelas Utama 1a, Kelas Utama 1b, Kelas 2 Dan Kelas 3, tanpa melakukan pemisahan pada masing-masing kelas sehingga data yang didapat bersifat general. Dari data yang diperoleh bahwa dalam 1 bulan rata-rata pasien rawat inap adalah 493 pasien.

Pelanggan yang diteliti adalah pelanggan yang berdomisili di kota Padang untuk memudahkan penelitian. Jumla $h$ populasi adalah jumlah rata- rata pelanggan perbulan yaitu 493 pelanggan (jumlah rata rata pelanggan umum 1 bulan).

\section{HASIL PENELITIAN}




\section{Karakteristik Responden Tentang}

\section{Bauran Pe masaran}

\begin{tabular}{|c|c|c|}
\hline $\begin{array}{c}\text { Variabel } \\
\text { Vabe }\end{array}$ & Frekuensi & Persentasi \\
\hline \multicolumn{3}{|l|}{ Umur Responden } \\
\hline $17-25$ & $17-25$ & $17-25$ \\
\hline $26-35$ & $26-35$ & $26-35$ \\
\hline $36-45$ & $36-45$ & $36-45$ \\
\hline $46-55$ & $46-55$ & $46-55$ \\
\hline $56-65$ & $56-65$ & $56-65$ \\
\hline Total & 175 & 100 \\
\hline \multicolumn{3}{|c|}{ Jenis Kelamin Responden } \\
\hline laki-laki & 71 & 40.6 \\
\hline Perempuan & 104 & 59.4 \\
\hline Total & 175 & 100 \\
\hline \multicolumn{3}{|c|}{ Pendidikan Responden } \\
\hline SD & 14 & 8 \\
\hline SMP & 11 & 6.3 \\
\hline SMU & 75 & 42.9 \\
\hline D3/Diploma/Sarjana & 61 & 36 \\
\hline Pascasarjana & 11 & 6.3 \\
\hline Total & 175 & 100 \\
\hline \multicolumn{3}{|l|}{ Pekerjaan Responden } \\
\hline Dagang/Wiraswasta & 34 & 19.40 \\
\hline Peg.swasta/Buruh & 47 & 26,80 \\
\hline Lain-lain & 94 & 40.48 \\
\hline Total & 175 & 100 \\
\hline \multicolumn{3}{|c|}{ Pendapatan Responden } \\
\hline$<2.000 .000 /$ bulan & 115 & 65.7 \\
\hline $\begin{array}{l}2.100 .000- \\
3.000 .000 / \text { bulan }\end{array}$ & 39 & 22.3 \\
\hline $\begin{array}{l}3.100 .000- \\
4.000 .000 / \text { bulan }\end{array}$ & 6 & 3.4 \\
\hline$>4.000 .000 /$ bulan & 15 & 8.6 \\
\hline Total & 175 & 100 \\
\hline \multicolumn{3}{|l|}{ Alamat Responden } \\
\hline Kota Padang & 147 & 84 \\
\hline Wilayah Sumbar & 20 & 11.4 \\
\hline $\begin{array}{l}\text { Wilayah Luar } \\
\text { Sumbar }\end{array}$ & 8 & 4.6 \\
\hline Kota Padang & 147 & 84 \\
\hline Total & 175 & 100 \\
\hline \multicolumn{3}{|l|}{ Frekuensi Rawatan } \\
\hline Pertama kali rawat & 115 & 65.7 \\
\hline $\begin{array}{l}\text { Lebih dari } 1 \text { kali } \\
\text { rawatan }\end{array}$ & 60 & 34.3 \\
\hline Total & 175 & 100 \\
\hline
\end{tabular}

2. Model 1

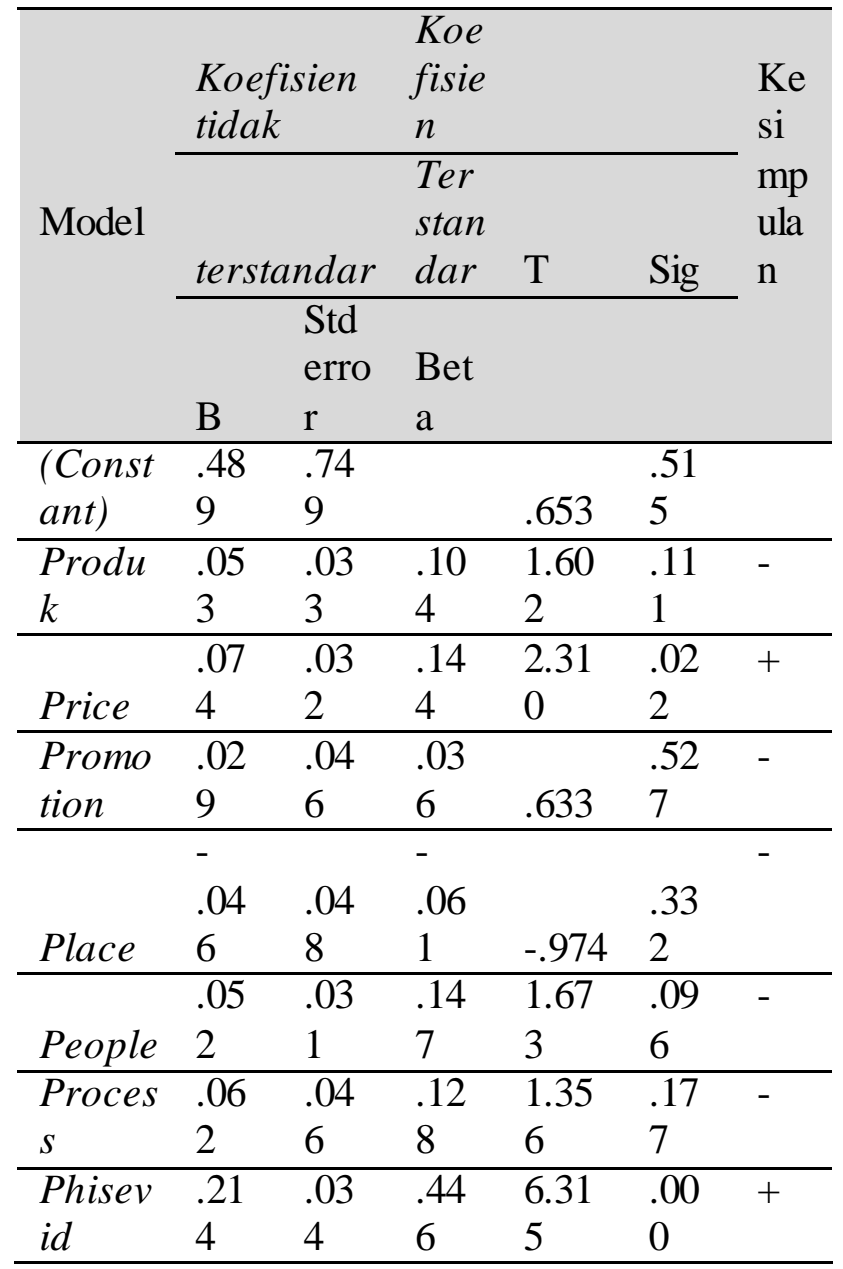

3. Model 2

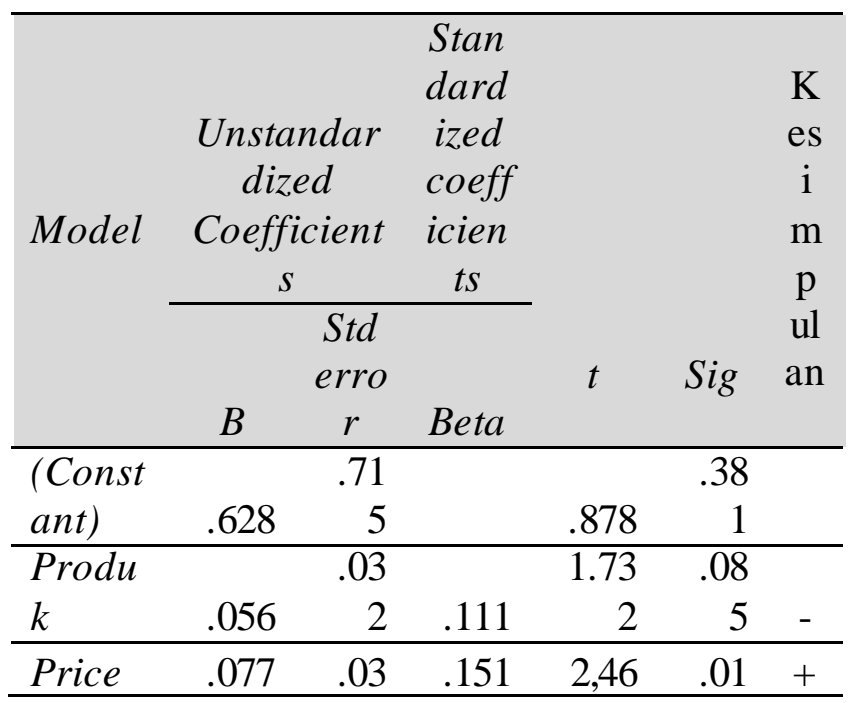




\begin{tabular}{lrrrrrr}
\hline & & 1 & & 9 & 5 & \\
\hline & & .04 & & & .36 & \\
Place & -.043 & 7 & -.057 & -.916 & 1 & - \\
\hline & & .03 & & 1.71 & .08 & \\
People & .054 & 1 & .151 & 6 & 8 & - \\
\hline Proces & & .04 & & 1.40 & .16 & \\
s & .064 & 6 & .132 & 4 & 2 & - \\
\hline Phisev & & .03 & & 6.35 & .00 & \\
id & .215 & 4 & .447 & 3 & 0 & + \\
\hline
\end{tabular}

4. Model 3

\begin{tabular}{lrrrrrr}
\hline & & erro & $\mathrm{a}$ & & & \\
& & $\mathrm{r}$ & & & & \\
\hline (Cons & .60 & .71 & & & .40 & \\
tant) & 0 & 4 & & .841 & 2 & \\
\hline Produ & .06 & .03 & .12 & 1.96 & .05 & - \\
$k$ & 2 & 2 & 2 & 2 & 1 & \\
\hline & .07 & .03 & .15 & 2.50 & .01 & + \\
Price & 8 & 1 & 3 & 5 & 3 & \\
\hline Peopl & .07 & .02 & .21 & 3.39 & .00 & + \\
$e$ & 6 & 3 & 5 & 6 & 1 & \\
\hline Physe & .21 & .03 & .45 & 6.95 & .00 & + \\
vid & 8 & 1 & 4 & 6 & 0 & \\
\hline & & & & & &
\end{tabular}

\begin{tabular}{|c|c|c|c|c|c|c|}
\hline \multirow{3}{*}{ Model } & $\begin{array}{l}\text { Unst } \\
\quad d i z\end{array}$ & $d$ & $\begin{array}{c}\text { Sta } \\
n d a \\
r d i z \\
e d\end{array}$ & & & \multirow{3}{*}{$\begin{array}{c}\mathrm{K} \\
\mathrm{es} \\
\mathrm{i} \\
\mathrm{m} \\
\mathrm{p} \\
\mathrm{ul} \\
\text { an }\end{array}$} \\
\hline & \multicolumn{2}{|c|}{$\begin{array}{c}\text { Coefficien } \\
\text { ts }\end{array}$} & $\begin{array}{c}\text { coef } \\
\text { ficie } \\
n t s\end{array}$ & $T$ & Sig & \\
\hline & $B$ & $\begin{array}{c}\text { Std } \\
\text { erro } \\
r\end{array}$ & $\begin{array}{c}\text { Bet } \\
a\end{array}$ & & & \\
\hline (Const & .57 & .71 & & & .42 & \\
\hline ant) & 3 & 3 & & .805 & 2 & \\
\hline & .05 & .03 & .10 & 1.63 & .10 & - \\
\hline Produk & 3 & 2 & 4 & 8 & 3 & \\
\hline & .07 & .03 & .14 & 2.44 & .01 & + \\
\hline Price & 6 & 1 & 9 & 2 & 6 & \\
\hline & & .03 & .13 & 1.56 & .11 & - \\
\hline People & .48 & 1 & 5 & 8 & 9 & \\
\hline Proces & .06 & .04 & .12 & 1.37 & .17 & - \\
\hline$s$ & 3 & 6 & 9 & 7 & 0 & \\
\hline Phisevi & .20 & .03 & .42 & 6.35 & .00 & + \\
\hline$d$ & 6 & 2 & 9 & 5 & 0 & \\
\hline
\end{tabular}

6. Model 5

\begin{tabular}{|c|c|c|c|c|c|c|}
\hline \multirow{4}{*}{ Model } & $\begin{array}{r}\text { Unstc } \\
\text { diz }\end{array}$ & & $\begin{array}{c}\text { Sta } \\
n d a \\
r d i z \\
e d\end{array}$ & & & \multirow[t]{4}{*}{$\begin{array}{l}\text { Kes } \\
\text { imp } \\
\text { ulan }\end{array}$} \\
\hline & \multicolumn{2}{|c|}{$\begin{array}{c}\text { Coefficient } \\
s\end{array}$} & $\begin{array}{c}\text { coef } \\
\text { ficie } \\
n t s\end{array}$ & $\mathrm{t}$ & Sig & \\
\hline & & $\begin{array}{l}\text { Std } \\
\text { erro }\end{array}$ & Bet & & & \\
\hline & $\mathrm{B}$ & $\mathrm{r}$ & $\mathrm{a}$ & & & \\
\hline Constan & 1.09 & .67 & & 1.62 & .10 & \\
\hline $\mathrm{t}$ & 5 & 4 & & 6 & 6 & \\
\hline & & .02 & .25 & 4.14 & .00 & + \\
\hline Price & .090 & 2 & 3 & 4 & 0 & \\
\hline & & .03 & .47 & 7.36 & .00 & + \\
\hline People & .229 & 1 & 7 & 5 & 0 & \\
\hline Phisevi & & .03 & .45 & 6.95 & .00 & + \\
\hline$d$ & .218 & 1 & 4 & 6 & 0 & \\
\hline
\end{tabular}

7. Hasil Pengujian Hipotesa

5. Model 4

\begin{tabular}{llll}
\hline $\begin{array}{c}\text { Hipotes } \\
\text { a }\end{array}$ & \multicolumn{1}{c}{ Pernyataan } & Nilai & $\begin{array}{c}\text { Keteranga } \\
\mathrm{n}\end{array}$ \\
\hline $\mathrm{X} 1$ & Variable price & 0.09 & $\mathrm{Ha}$ \\
& $\begin{array}{l}\text { diterima } \\
\text { terpengaruh } \\
\text { keputusan } \\
\text { memilih }\end{array}$ & 0 & $\begin{array}{l}\text { dan Ho } \\
\text { ditolak }\end{array}$ \\
& Variable people & 0.22 & Ha \\
& $\begin{array}{l}\text { diterima } \\
\text { berpengaruh } \\
\text { terhadap } \\
\text { keputusan }\end{array}$ & 9 & $\begin{array}{l}\text { dan Ho } \\
\text { ditolak }\end{array}$ \\
& memilih & & \\
\hline X3 & Variable & 0.21 & Ha \\
\hline & & & \multicolumn{2}{c}{275}
\end{tabular}




\begin{tabular}{lll}
\hline physical & 8 & $\begin{array}{l}\text { diterima } \\
\text { dan Ho } \\
\text { evidence } \\
\text { ditolak } \\
\text { terpengaruh }\end{array}$ \\
$\begin{array}{l}\text { keputusan } \\
\text { memilih }\end{array}$ & & \\
\hline
\end{tabular}

Dengan demikian, model regresi terakhir ini sudah memadai untuk memprediksi keputusan memilih pelanggan Rumah Sakit Ibnu Sina untuk rawat inap sebagai variabel dependen.

Setelah uji regresi berganda didapatkan maka akan diuji apakah terdapat multikolinieritas, heteroskedistas dan normalitas antar variable independent. Variabel yang baik adalah berbentuk normal, tidak terdapat multikolinieritas dan heteroskedisitas.

\section{PEMBAHASAN}

Dari penelitian ini produk, ternyata bermakna tidak signifikan. Jadi Produk tidak mempengaruhi keputusan pelanggan untuk rawat inap di Rumah Sakit Ibnu Sina Padang. Dapat dipahami bahwa produk-produk yang ada di Rumah Sakit Ibnu Sina tidak berbeda jauh dengan rumah sakit swasta lainnya di kota Padang. Dalam artian produk - produk yang ditawarkan oleh rumah sakit seperti dokter yang berpraktek di Rumah Sakit Ibnu Sina sudah berkualitas dan lengkap. Kelengkapan jenis spesialisasi dokter di Rumah Sakit Ibnu Sina sudah dirasakan mencukupi untuk kebutuhan pelanggan rawat inap. Demikian juga dengan kelengkapan obat-obatan, karena pasien tidak perlu mencari obat yang dibutuhkan keluar rumah sakit. Rumah sakit juga menyediakan obatobatan khusus yang dibutuhkan pasien bila diperlukan dengan cara memesan langsung pada distributor.

Pada penelitian ini diketahui bahwa harga mempengaruhi responden untuk mendapatkan rawat inap di Rumah Sakit Ibnu Sina. Harga signifikan mampu mempengaruhi proses keputusan pelanggan untuk mendapatkan layanan rawat inap di Rumah Sakit Ibnu Sina. Rawat inap di Rumah Sakit Ibnu Sina mempunyai beberapa kelas perawatan yang berbeda tarif dan fasilitas akomodasinya.

Harga juga merupakan biaya yang ditimbulkan pelanggan dalam memperoleh manfaat suatu produk jasa. Namun jika mutu produk tinggi maka pelanggan tidak akan segan untuk membayar lebih mahal selama masih berada dalam keterjangkauan $\operatorname{mereka}^{(7)}$

Penelitian ini mendapatkan adanya korelasi yang positif antara harga dengan proses keputusan memilih, sehingga bila harga dinaikkan maka keputusan memilih rawat inap juga akan naik. Penelitian ini mendapatkan bahwa responden menilai tarif rumah sakit secara keseluruhan sudah terjangkau sehingga harga mempengaruhi secara signifikan proses keputusan rawat inap. Variabel keterjangkauan tarif ada pada rawat inap secara keseluruhan, keterjangkauan tarif obat-obatan, 
keterjangkauan tarif laboratorium, tarif akomodasi, dan terakhir keterjangkauan tarif visite dokter, tarif juga dinilai sudah sesuai dengan pelayanan yang diterima. Bila dihubungkan dengan tingkat ekonomi responden maka tarif rawat inap Rumah Sakit Ibnu Sina dapat dianggap sesuai dengan tingkat ekonomi responden yang juga dapat dihubungkan dengan kesesuaian tarif dengan kelas rawatan yang dipilih.

Pada penelitian ini diketahui bahwa tempat tidak mempengaruhi responden untuk memilih rawat inap. Tempat tidak mempengaruhi keputusan memilih rawat inap dirumah sakit. Bila hal ini dapat dihubungkan dengan domisili responden yang paling banyak adalah berasal dari kota Padang, maka dapat dipahami karena pelanggan rawat inap yang membutuhkan pelayanan cenderung untuk memilih tempat pelayanan yang lebih dekat dengan domisili tempat tinggalnya dengan pertimbangan cepat mendapatkan pertolongan, dekat waktu membesuk dan sebagainya. Kestrategisan letak rumah sakit juga dihubungkan dengan tersedianya fasilitas umum karena selama perawatan pelanggan akan membutuhkan fasilitas umum tersebut. Fasilitas umum yang sering dibutuhkan oleh pelanggan adalah ketersediaan ATM, kantin yang memadai, tempat ibadah dan rasa keamanan dan kenyamanan bila dihubungkan dengan peta tsunami yang berada pada wilayah kuning.
Lokasi adalah tempat dimana dan bagaimana jasa akan diserahkan, sebagai bagian dari nilai dan manfaat dari jasa. Untuk tipe interaksi dimana pelanggan mendatangi penyedia jasa seperti rumah sakit, maka letak lokasi menjadi sangat penting, karena memerlukan pertimbangan yang cermat dari beberapa faktor seperti; akses yang mudah dijangkau, visibilitas (mudah terlihat), lalu lintas, persaingan dan peraturan pemerintah. Jadi lokasi yang strategis dan mudah dicapai kendaraan umum, akan menjadi daya tarik tersendiri(7), dan sebagai tempat, rumah sakit juga harus memberikan kesempatan untuk mudah dicapai dan memerlukan waktu yang relatif singkat ${ }^{(8)}$

Pada penelitian ini diketahui bahwa promosi tidak mempengaruhi responden untuk mendapatkan rawat inap. Dari hasil uji regresi berganda didapatkan bahwa promosi tidak berpengaruh terhadap keputusan pelanggan dalam memilih rawat inap di rumah sakit Ibnu Sina. Sehingga promosi tidak berpengaruh terhadap keputusan memilih rawat inap di Rumah Sakit Ibnu Sina. Maka dapat dipahami bahwa Rumah Sakit Ibnu Sina belum mengembangkan sisi promosi melalui media cetak ataupun elektronik untuk mempromosikan produk dan layanan apa saja yang sudah bisa didapatkan pelanggan. Artinya pelanggan rumah sakit selama ini mengetahui produk layanan adalah dari mulut ke mulut atau dari 
rujukan dokter. Promosi melalui leaflet dan brosur yang berisi jenis layanan yang tersedia di Rumah Sakit Ibnu Sina sekarang tidak ada sama sekali. Menurut Lovelock, Tidak satupun program dapat berhasil tanpa adanya program komunikasi yang efektif yang memberikan promosi dan pendidikan. Komponen ini juga memainkan tiga peran penting yaitu menyediakan informasi dan saran yang dibutuhkan, membujuk pelanggan sasaran tentang kelebihan suatu produk dan mendorong pelanggan untuk mengambil tindakan pada suatu waktu. Dalam pemasaran jasa, banyak komunikasi bersifat mendidik, khususnya bagi pelanggan baru. Perusahaan dapat mengajarkan mereka tentang manfaat jasa, dimana, dan kapan mendapatkannya dan terlibat dalam proses ${ }^{(9)}$

Pada penelitian ini diketahui bahwa personel signifikan mempengaruhi proses keputusan pelanggan untuk mendapatkan layanan rawat inap di rumah sakit Ibnu Sina. Maka people berpengaruh terhadap keputusan memilih rawat inap di Rumah Sakit Ibnu Sina. Hal ini berarti responden menilai pelayanan yang diberikan dokter meyakinkan dan menilai petugas loket ramah dan seragam perawat adalah baik dan rapi, petugas obat ramah dan pakaian dokter baik dan rapi.

Pada penelitian ini diketahui bahwa proses tidak mempengaruhi keputusan pelanggan untuk mendapatkan rawat inap di
Rumah Sakit Ibnu Sina. Proses tidak mempengaruhi responden dalam keputusan memilih rawat inap di Rumah Sakit Ibnu Sina. Dalam artian responden belum menilai alur penerimaan pasien lancar dan tertib, waktu pemeriksaan dokter dan cara pemberian obat tepat, dokter yang sopan dan informasi tentang obat juga informasi petugas loket yang jelas dan lengkap belum berpengaruh terhadap proses keputusan rawat inap. Proses dalam rumah sakit lebih banyak diartikan sebagai standar operasional prosedur. Sehingga bila SOP dilaksanakan dengan tertib, maka tidak akan banyak keluhan dari pelanggan akibat bervariasinya layanan yang diperoleh. SOP yang ada harus dikomunikasikan kepada pelanggan sehingga tidak menimbulkan salah persepsi. Proses tidak mempengaruhi proses keputusan rawat inap pada rumah sakit Ibnu Sina.

Pada penelitian ini diketahui bahwa bukti fisik mempengaruhi responden untuk mendapatkan rawat inap di Rumah Sakit Ibnu Sina. Bukti fisik mempunyai kemampuan untuk mempengaruhi proses keputusan pelanggan dalam rawat inap di Rumah Sakit Ibnu Sina. Variabel bukti fisik seperti kesesuaian kondisi ruang rawat dengan kelas yang dipakai, kamar mandi yang terawat dan bersih, kamar rawat inap yang aman dan nyaman, suasana rumah sakit yang nyaman dan asri, tempat parkir yang luas dan aman dan ruang untuk menunggui pasien yang memadai dan nyaman 
mempengaruhi proses keputusan rawat inap di Rumah Sakit Ibnu Sina. Dapat dipahami bahwa responden mencari rasa aman dan nyaman ketika sedang dalam perawatan di rumah sakit untuk percepatan kesembuhan penyakitnya.

\section{KESIMPULAN}

1. Variabel pengaruh bauran pemasaran yang berpengaruh terhadap keputusan pelanggan rawat inap di Rumah Sakit Ibnu Sina Padang, adalah Price, Physical Evidence dan People.

2. Variabel bauran pemasaran yang tidak berpengaruh terhadap keputusan pelanggan rawat inap di Rumah Sakit Ibnu Sina Padang adalah product, process, place, promotion

\section{SARAN}

1. Diharapkan kepada Rumah Sakit Ibnu Sina Padang untuk menurunkan biaya layanan bagi pasien sesuai dengan staus sosial ekonomi masyarakat disekitar wilayah Rumah Sakit Ibnu Sina Padang. Diharapkan Kepada Rumah Sakit Ibnu Sina Padang untuk meningkatkan kualitas bukti fisik layanan kesehatan seperti peralatan yang representatif, interior bangunan yang asri, eksterior bangunan, fasilitas parkir, kantin, bank, dan jaminan keamanan. Kepada Rumah Sakit diharapkan untuk menyampaikan kepada karyawannya untuk meningkatkan perilaku efektif karyawan dan departemen rumah sakit yang dapat menarik pelanggan karena setiap karyawan memiliki dampak pada pelanggan dan harus melihat pelanggan sebagai sumber kesejahteraan perusahaan.

2. Diharapkan kepada Rumah Sakit Ibnu Sina Padang untuk meningkatkan kualitas product yang dihasilkan dari rumah sakit agar keinginan masyarakat untuk mempergunakan layanan kesehatan dari Rumah Sakit Ibnu Sina Padang. Kepada Rumah Sakit Ibnu Sina Padang untuk meningkatkan process peningkatan mutu rumah sakit. Kepada tim promosi di Rumah Sakit diharapkan untuk merancang media promosi yaitu bagaimana pasien tahu tentang jenis pelayanan yang ada di Rumah Sakit, bagaimana mereka termotivasi untuk menggunakannya, bagaimana mereka kemudian memang benar-benar menggunakannya, lalu menggunakan secara berkesinambungan dan menyebarkan informasi itu kepada rekanrekannya.

\section{DAFTAR PUSTAKA}

1. Kementrian Kesehatan Republik Indonesia. 2010 Peraturan Kementrian Kesehatan Indonesia. Jakarta.

2. Setiawan, S. 2011. Loyalitas Pelanggan Jasa, Studi Kasus Bagaimana Rumah Sakit Mengelola Loyalitas Pelanggannya, IPB Press. Bogor. 
3. Hartono,B. 2010. Manajemen Pemasaran

Untuk Rumah Sakit. Rineka Cipta.

Jakarta.

4. Kottler \& Keller. 2009. Manajemen Pemasaran jilid 1 dan 2 . Erlangga. Jakarta.

5. Setiawan, S. 2010. Loyalitas Pelanggan Jasa , Studi Kasus Bagaimana Rumah Sakit Mengelola Loyalitas Pelanggannya, IPB Press. Bogor.

6. Rumah Sakit Islam Ibnu Sina Padang. 2001. Rencana Program Kerja Anggaran Pendapatan Dan Biaya Yarsi Sumbar Tahun 2011. Padang.

7. Alma, Buchari \& Hurriyati, Ratih. 2008. Manajemen corporate dan strategi pemasaran jasa pendidikan. Alfabeta, Bandung.

8. Supriyanto.MS.E \& Ernawati. 2010. Pemasaran Industri Jasa Kesehatan. Penerbit. Jogyakarta.

9. Lupiyoadi, H. 2008. Manajemen Pemasaran Jasa. Salemba Empat. Jakarta. 